\title{
The Merger of Rural Primary Care and Home Health Services*
}

\author{
Howard S. Zuckerman and Dean G. Smith
}

\begin{abstract}
The merger of rural primary care and home health services offers the potential for increasing the administrative efficiency of health care, and thereby enhancing the quality of care and increasing access to services, particularly health promotion. However, the proposed bencfits of any merger can only be realized if the merger process is successfully completed. An analysis of the factors that were important in a case study of successful and unsuccessful mergers of rural health centers and home health care agencies in northeastern Vermont is presented. Three components were found to be necessary to start the merger process: complementary needs, opportunity, and common philosophy. The incolvement and support of key individuals was crucial to sustaining merger interest. Good communication throughout the process contributed substantially to the muintenance of both community and staff support. Others considering similar mergers should recognize that the process of consolidating organizations and satisfying regulations takes some time to complete.
\end{abstract}

According to a recent survey, the two highest ranking concerns of rural health centers were: (1) their ability to attract or retain qualified health practitioners; and (2) the limited financial resources of their clients (Joint Rural Task Force, 1988). The maldistribution of health practitioners has long been a problem in rural areas. Nearly half of the rural health centers surveyed perceived worsened economic conditions, and nearly 60 percent indicated that their Public Health Service funding had been reduced, requiring cutbacks of services and personnel in many cases (Joint Rural Task Force, 1988).

In response to the staffing and financial difficulties facing community health centers, many are seeking organizational changes and more stable sources of funding as alternatives to reducing services. Mostly in response to changes in professional staffing, almost half of rural health centers changed their organizational structures in some way during 1981 to 1982 (Sheps et al., 1983). And during 1983 to 1984, 75 percent of a sample of community health centers expanded or initiated the coordination of services with other organizations (Wood, Hughes, \& Estes, 1986). In this latter

\footnotetext{
* This project was supported by a grant from the W.K. Kellogg Foundation. Requests for further information should be sent to: Dean Smith, $\mathrm{PhD}$, Department of Health Services Management and Policy, The University of Michigan, 1420 Washington Heights, Ann Arbor, MI 48109-2029.
} 
survey, the coordination of services for the elderly was cited as an area of particular promise due to the possibility of Medicare payment.

This is a report on one alternative that may be viable for many rural health centers-merging with home health services. Thereare many potential benefits from integrating rural primary health care and home health services. These anticipated benefits include improved organizational efficiency and financial stability, and enabling organizations to attract and retain qualified practitioners. However, the benefits of any merger or consolidation of services can only be realized if the merge process is completed successfully. While obvious, it is not often realized how many mergers, joint ventures, and other affiliations are initiated, but not completed (Sandrick, 1986). To demonstrate and examine the process of merging rural primary care and home health services, a set of northeastern Vermont health facilities were awarded a demonstration grant from the W.K. Kellogg Foundation. This is a report on the evaluation of that demonstration.

\section{The Unification Process}

The process of organizational unification can be thought of as having four stages (Starkweather, 1981). The concepts underlying each stage are first described generally, and are applied to this case in later sections. The first stage is the pre-existing condition of the organizations and the market. This stage includes the nature of the services provided and the financial viability of the involved organizations, as well as the community decisionmaking process. The second stage concerns the enabling forces, or the impetus toward unification, that reflect the sequences of events leading to the decision to unify. This stage includes the relative status and power of lay groups (and their intentions), and the costs and opportunities for benefits as a result of unification. With the actual unification of services, the third stage involves the process of unification and the immediate effects of the unification on the organizations involved. These immediate effects include responses by the community to the merger and strains within the organization. The final stage is the stabilization of the organization, at which time the effects of the unification can begin to be evaluated. After the mechanics of unification have been completed, the relationships between involved parties mature into their ultimate forms and permit the testing and assessment of merger results.

Following a brief discussion of the methods used to collect information for this case study, sections focus on each of these four stages for the case of a demonstration project involving rural health centers and home health agencies in northeastern Vermont. Finally, some conclusions are drawn from this demonstration. 


\section{Case Study Methods}

An evaluation by external reviewers was included as part of the W.K. Kellogg Foundation grant supporting the demonstration project. Given the nature of the demonstration-mergers among a small number of organizations--a case study method of evaluation was selected. Information for this case study was collected in three ways: site visits; interviews and written communication with participants and community leaders; and review of financial reports and other documents.

Two site visits were made to northeastern Vermont, one at the end of the first year and one near the end of the project. During these site visits, meetings were held with all of the involved program directors, selected board members and a variety of community leaders. A follow-up written survey was sent to a number of community leaders, asking for any insights on the merger process and outcomes to date. Almost all of the written comments submitted were consistent with the verbal discussions. A more detailed examination of the survey responses is reported elsewhere (Smith \& Zuckerman, in press). Similarly, the financial reports and other documents that were prepared by the involved organizations suggested that the information received from personal interviews about the status of the organizations was quite accurate. Thus, the information contained in the financial reports is not separately reported here.

While by their very nature case studies involving small numbers of organizations provide limited opportunity for statistical verification, the consistency of the messages received from various persons and sources in this study suggests at least a plausible demonstration of the types of experiences merging health centers and home health agencies might encounter. Others considering similar types of organizational affiliations would be advised to consider these experiences, in light of their own particular conditions.

\section{Pre-Existing Conditions: The Northeast Kingdom}

The geographic area that encompasses the health care organizations that were to be unified is called the "Northeast Kingdom," a 2,000-square-mile, tricounty area bounded on the north by Quebec and on the east by New Hampshire. The service areas of the health centers and the home health agencies cover 16,000 and 25,000 of the 57,000 residents of the Northeast Kingdom, respectively. The average per capita income in the Northeast Kingdom is among the lowest in the country $(\$ 8,645$ in 1985), and 22 percent of the population has incomes under the poverty level (Office of Economic Opportunity, 1987). This area has problems of disproportionate need at 
both ends of the age spectrum. Teenage mothers account for 50.3 of each 1,000 births in the region (Vermont Department of Health, 1989), and the area has the highest percentage in the state of elderly persons over age 75 living at home (Vermont Department of Health, 1988).

Primary care services were being provided by two hospitals and five health centers. The five health centers were all centrally administered by Northern Counties Health Centers, Inc. (NCHC) and distributed throughout the Northeast Kingdom, each being 10 to 25 miles from the nearest hospital. All of the health centers offered the required primary health services called for by the Rural Health Initiative; i.e., a full range of office medical care, treatment of acute illness (colds, earaches, minor injuries), chronic illness (arthritis, high blood pressure), physical exams, and lab tests (blood tests, pregnancy tests, urinalysis). The health centers also provided certain health promotion and community health services. In addition, one health center also provided dental services, and another served as a satellite office for the mental health agency and a regional hospital's physical therapy unit. Services were provided by nurse practitioners, physician assistants, and physicians, when available.

Home health services were provided by two home health care agencies. The Caledonia Home Health Care Agency (CHHCA) was started nearly 20 years ago by its first and only director, until the merger. The Orleans and Northern Essex Home Health Care Agency (ONEHHCA) was originally started in 1969 as a program of Northeast Kingdom Mental Health Service (NKMHS), and in 1974 became a separate entity under its own director. Both agencies were accredited and Medicare certified.

Home health services have been a benefit covered by Medicare since 1966. Home health agencies have been shown to provide an opportunity for cost savings and health services integration (Deprez, Pennell, \& Libby, 1987). The rates of use of home health services varies significantly across states, with an average of 45 enrollees per 1,000 population and a high of 72.5 in Vermont (Kirby, Latta, \& Helbing, 1986).

Mental health services were provided by a single agency, NKMHS, which offered a wide range of mental health and health education services. Community mental health offices were located in two towns, and child mental health services were offered in two others. The NKMHS also participated in the health centers' adolescent pregnancy programs.

All of the aforementioned health services providers had a history of cooperation in regional health programs and had been supported by their communities. A number of joint ventures had been undertaken in the past, particularly for providing services to adolescents and the elderly.

\section{Impetus toward Unification}

As is the case at many other health centers, patients' finances and staffing were a concern at $\mathrm{NCHC}$, and a concern to the potential merger partners. In 
the two years prior to the merger, the health centers had experienced small operating losses and were in need of capital funds for the replacement of facilities. The health centers were also in need of additional physicians to meet the demand for services. These concerns led to NCHC's concerted efforts in 1984 and 1985 to find alternative arrangements for financing and providing services.

At the same time (1984 to 1985), discussions among many CHHCA board members and staff had started to take place concerning the pending retirement of their director. Recognizing that there could be some gains from an affiliation with the health centers, and the interest and ability of the health centers' director to manage the home health agency, discussions were along the lines of a merger or consolidation almost from the beginning. In a study involving the integration of hospice and home health services, having similar types of patient needs, the potential for sharing provider and administrative staff, and common strategies were identified as being important factors leading to successful integration (Smith \& Reid, 1987). This type of hospice and home health services integration had already taken place within CHHCA prior to the merger. A further expansion into primary care services, again with similar patients, shared providers, and administrators, was viewed by CHHCA board members as an attractive alternative.

Prindaville, Sidwell, and Milner (1983) have suggested that having an opportunity is an important prerequisite to successfully integrating programs. Starkweather (1981) presented a more specific proposition that mergers are more likely when both organizations "face crises." While neither the financial and staffing difficulties of the health centers nor the retirement of the CHHCA director may have been crises, they certainly presented an opportunity for the organizations to consider consolidation.

Consistent with further propositions offered by Starkweather (1981), the initial merger discussions began with a small group of persons, mostly NCHC and CHHCA board members. In addition to their substantive value, these discussions also served to bring the key leadership of both organizations together. The discussions were said to be open and candid, and enabled board members to get to know one another. Involved board members reported that comfort levels improved, and new relationships, "based on trust and mutual respect," emerged. While board members of each organization sought to retain some degree of organizational identity and integrity, and did not wish to jeopardize their local support, financial status, quality, or ability to raise funds, they came to see the benefits of consolidation. These were, after all, two organizations, each with a community health focus and with overlapping service areas. As one board member noted during the interviews, "it made sense to get together."

These discussions led to consultant studies. In the early part of 1985, a consulting firm associated with a government-funded project to provide planning assistance to rural health centers was engaged to develop strategic plans for NCHC. After a series of interviews and organizational evaluations, the consultant suggested to NCHC and CHHCA that a two-track approach 
to affiliation was needed for the organizations to develop into a strong and integrated health care system. These two tracks included first, immediate NCHC-CHHCA affiliation, and second, long-range planning and possible additional affiliations with the area agency on aging, the regional mental health agency, and the regional hospitals. The consultant also warned that "considerable attention should be paid to political, corporate, staffing, financial, and legal concerns."

Northern Counties Health Centers expanded the ideas presented in the consultant report into a demonstration project proposal to the W.K. Kellogg Foundation. The proposal outlined a demonstration to improve rural health services by accomplishing five tasks: (1) computerizing health center and home health case records; (2) integrating the delivery of health services by utilizing the common computerized records; (3) assessing the quality of care, again utilizing the computerized records as a data base; (4) merging of Northern Counties Health Centers with Caledonia Home Health Care Agency and Orleans and Northern Essex Home Health Care Agency; and (5) expansion of joint ventures with Northeast Kingdom Mental Health.

While the detailed discussions that had taken place between NCHC and CHHCA had not included ONEHHCA and NEKMH, some preliminary conversations between $\mathrm{NCHC}$ 's director and the directors of ONEHHCA and NEKMH indicated that they would be interested in exploring options, including a merger, for coordinating services. Letters of support from CHHCA, ONEHHCA, and NEKMH were included in the proposal. However, none of the letters committed the organizations to a merger, only planning.

The proposal, approved for a three-year period (1986 to 1989) provided funding for salary support for program staff, facilities renovation, legal and financial consulting, quality of care research, and general office supplies. Funding was also provided for "bricks and mortar," in this case computer hardware and software to integrate information systems, and office renovations. Given the financial conditions of the organizations prior to the merger, it is unlikely that computerization of records could have occurred without grant support.

The process of merging NCHC and CHHCA began immediately. The process of including ONEHHCA, however, proved to be short lived. Although direct attribution is difficult, at least three key factors that attracted CHHCA to the merger process were not present with ONEHHCA. First, ONEHHCA did not have an immediate need for new leadership. Second, unlike the open discussions at CHHCA, ONEHHCA board members did not entertain similar merger proposals, nor were these discussions encouraged by any key individuals. Third, ONEHHCA felt that a broader affiliation with other home health agencies or hospitals in Vermont might be a better approach to preserving home health than the strictly local approach. This philosophy was not inconsistent with the recommendations from a separate long-range plan that had been prepared by a consultant for 
their organization in 1986. ONEHHCA chose to explore a strategy of horizontal integration with similar agencies in other parts of the state rather than vertical integration with related agencies within their service area.

It is important to note that both home health agencies selected strategies of cooperation with other health care organizations rather than competition with one another. The benefits of selecting cooperation over competition is supported as one of Moscovice's (1989) principles for promoting viable rural health care systems.

This case study suggests that at least a few components may be necessary to start the merger process: need, opportunity, and a common philosophy. In the eventually successful merger of $\mathrm{NCHC}$ and $\mathrm{CHHCA}$, all three were present. In the failed attempt with ONEHHCA, only the opportunity was present, while neither the immediate need nor a common philosophy were in place.

\section{Dynamics of Implementation}

Financial logistics were quite important both before the merger and during the process. Before the merger, CHHCA was concerned about the short-run financial status of the health centers. The W.K. Kellogg Foundation grant greatly reduced this concern by offering financial support for both staffing and equipment during the three-year merger process. During the course of discussions, the ability of both organizations to qualify for continued funding from their major previous sources (i.e., the Rural Health Initiative and Medicare) was also a concern. Final unification was delayed for several months as consultants and staff explored the necessary steps to assure funding. While it was eventually discovered that there were no regulations that prohibited such a merger, the fact that this was the first case that the regulators had considered required extensive examination of the regulations and numerous meetings with regulators. Others considering similar mergers would be advised to contact their local regulators early in the process to avoid similar delays.

Another financial consideration was the local support provided to the health centers and home health agencies. Towns and communities in northeastern Vermont provided significant contributions to health services in terms of donations of money and volunteering of time. Cash donations accounted for 6.5 percent of total revenues for the merged organization in 1989. Initial discussions with board members and other persons involved with the merging organizations revealed that almost all of the persons affiliated with the health centers were aware of the activities of the home health agencies. However, persons affiliated with the home health services were generally only knowledgeable about the particular health center closest to their town, and not the entire system. Therefore, to promote the continuing community support of health services, part of the merger 
process involved educating the community home health leaders about the system of health centers. Staff and board meetings, and frequent informal discussions were all used to keep people informed of the process. Communication and education among staff and supporters of both organizations was considered to be an important part of the unification process.

Through the education and discussion process, it was made clear that the communities wanted the identity of the individual health centers and home health agency to be preserved throughout the merger. This is consistent with Starkweather's (1981) propositions regarding mergers of community hospitals, and with Moscovice's (1989) principles for rural health care systems. Preserving local leadership and empowerment, and building community involvement are cited as two important principles for promoting viable rural health care systems.

In an effort to avoid perceived regulatory problems, the original proposal included the formation of a holding company that would own the health centers and the home health agencies. However, it was quickly discovered that this type of arrangement would involve much additional regulatory reporting and approval, and unnecessarily add to the cost of the organization. The holding company plan was not used and, instead, there was a simple merger of the organizations into a new single corporation, Northern Counties Health Care, Inc. The governance structure of the merged organization was an expansion of the structure used by the community health centers. Previously, individual health centers had local standing committees, with each having representation on a corporate board. The addition of home health services led to one additional standing committee, replacing the former home health care agency board, and additional members on the corporate board. As it turned out, permitting the health centers and home health care services to retain their original names as product lines within the new corporation simplified the logistics of the merger as compared to the original plan, and pleased some board members by "allowing for the continuation of community support" through the standing committees.

Finally, the NCHC-CHHCA merger was approved by the Region I Office of the U.S. Public Health Service and by the Office of the Vermont Secretary of State in July 1988, and was completed with the election of new board of directors in October 1988. The Internal Revenue Service continuation of tax exemption notification was signed in December 1988.

\section{Stabilization}

While incomplete, the efforts supported by the W.K. Kellogg Foundation furthered the goal of unifying health care in northeastern Vermont. By the end of the grant period, three of the five objectives of the proposal had been met. Health center (NCHC) and home health (CHHCA) records had been computerized, and all health centers were linked by computer for centralized 
service and financial reporting. The merger of Northern Counties Health Centers and Caledonia Home Health Care Agency was finalized. The joint ventures proposed with Northeast Kingdom Mental Health Services were modest, but were met to some degree with the expansion of health promotion programs. As noted, efforts to consolidate Orleans and Northern Essex Home Health Agency were unsuccessful. Also unsuccessful were efforts to assess the quality of care provided by the merged organizations. Attempts to recruit quality-of-care researchers to examine the new data source found no interested parties. This was largely due to the newness of the data source, and the scarcity of qualified researchers. The W.K. Kellogg Foundation permitted monies that had been designated for quality assessment to be used for the installation of additional computer equipment and supplies at one of the health centers.

The proposed benefits of unifying services focused on increasing the administrative efficiency of health care, enhancing the quality of care, and increasing access to services (particularly health promotion). Through a single administrative structure it was possible in this case to increase the efficiency of reporting requirements. The previously separate administrative functions of the health centers and home health were relocated to a new common building, next to a local hospital. And the administrative, financial, and medical information of the merged organizations were computerized. While neither organization alone could justify the costs of a new building, a computer system, or a full-time financial director, each became feasible under a combined organization buttressed with grant support. Again, while many of the organizational aspects of the merger may have occurred without the grant, the computerization, facilities renovation, and legal consultation required outside support.

Actual cost and efficiency gains from consolidating reporting and administrative services are very difficult to detect given the number of events affecting the merged organizations. However, there is every indication that costs, particularly fees to patients, were not adversely affected. Further, cost recovery has been increased through improved reporting and grant processing.

Service gains, in terms of access, availability, and quality were not expected by board members and administrative staff to be broad, although there was an increase in services, particularly in the area of health education and health promotion. The merger and W.K. Kellogg Foundation grant were cited by staff and community leaders as contributing factors in the receipt of a competitive Adolescent Family Life Demonstration (AFLD) Project grant from the Department of Health and Human Services, Office of Adolescent Pregnancy Programs. The AFLD Project also served as the basis for a number of NEKMH joint ventures which were called for in the W.K. Kellogg Foundation grant, and involved ONEHHCA, affirming cooperative efforts among the organizations even without merger. The separate contribution of each grant to the overall performance cannot be determined, 
but family services have been expanded.

The merger also was cited by administrative and medical staff as a contributing factor in the recruitment of new health center physicians. The availability of health services in rural areas and the financial viability of rural health centers are closely linked to a community's ability to attract qualified professional staff. Adequate support facilities is one of the most important factors affecting physicians' initial decisions to practice in rural areas and their decisions to remain (Movassaghi \& Kindig, 1989). A new physician was attracted to the health center at Island Pond by the merger and the increased cooperation among local services which expanded opportunities for professionals in the northern counties.

\section{Conclusions}

This project showed that it is feasible and permissible, within the scope of regulations, to merge rural health centers and home health agencies. Each of a number of different reporting agencies and sources of funding for these organizations have requirements that must be met prior to the completion of a merger. The process of exploring the rules and procedures governing this type of endeavor was time consuming. However, these rules are now known and need not be rediscovered. Others considering similar mergers should recognize that the process of satisfying regulations takes some time to complete. At a concluding interview, the administrator noted that "three years to merge four established organizations was probably overly ambitious."

This case also showed that it is possible to merge organizations with long, independent histories of community support without losing the community support for any organization, and, in fact, support might even increase. Good communication between the administrative staff and the community, using both formal mechanisms such as staff and board meetings, as well an informal discussions, contributed substantially to the maintenance of both staff and community support.

Having a common philosophy was identified as being an important factor in the merger process by both individuals involved in the process and stakeholders in the community. Having a strategic opportunity and need for consolidation were also important aspects of the successful merger. Caledonia Home Health Care Agency's need for a director coincided with Northern Counties Health Centers' financial concerns and desire to expand. Theorganizations that did not merge had neither the need for new leadership nor the financial or other pressures that would necessitate an organizational change. All organizations, however, agreed that cooperative solutions were appropriate. And, even though Orleans and Northern Essex Home Health Care Agency did not merge into the new organization, it continues to be involved with joint ventures for providing services. 
Some of the proposed benefits of unifying services were realized during the grant period: the single administration increased efficiency, permitted the use of a new building and computer system, and increased cost recovery. While it is unlikely that service gains from the merger would have permitted sufficient excess revenues to purchase the computer system, the scale of the merged organizations made its use cost effective. The unification also expanded opportunities for professional staff, which attracted at least one new physician to the region.

One proposed long-range benefit of the merger was the start of a rural health maintenance organization (HMO). This was one aspect of the merger that was highlighted in the W.K. Kellogg Foundation's award of the grant. The development of a rural HMO will require, eventually, the merger of these organizations, and the interest of area physicians and hospitals. At least one local physician group practice has expressed interest in some affiliation with the new organization, and others are being approached. While any development of an HMO in this area could not be expected for at least five to 10 years, this merger may later be cited as a starting point.

The project also served two broader purposes. First, it reaffirmed the utility of Starkweather's (1981) model of stages to understand the process by which, and the conditions under which, organizations come together (or, as indicated, when they do not). Second, the project addressed the kinds of outcomes that can result from unification. On the one hand, merger or consolidation can lead to positive results, such as controlling the rate of increase in costs by rationalizing and coordinating the delivery of services and reducing duplication and excess capacity. On the other hand, negative results can accrue. A substantial sum of money was spent on computers, renovations and legal advice to facilitate the merger. Had the merger not been funded by a foundation grant, many of these items that led to the administrative efficiencies may not have been available. And even with the grant support, had many more legal, regulatory or other "unexpected surprizes" occurred, the financing available for the merger might not have been sufficient. The evidence from the creation of a unified health system in northeastern Vermont, while limited, nevertheless suggests that the results achieved clearly tend to be the positive, and that the public interest is being served.

\section{REFERENCES}

Ashby, J. (1981). Management and community factors affecting the financial viability of rurai health initiative sites. Journal of Ambulatory Care Management, 4, 1-13.

Banahan, B., \& Sharpe, T. (1982). Evaluations of the use of rural health clinics: Knowledge, attitudes and behaviors of consumers. Public Health Riports, 97, 261-268.

Biggs, E.L. (1977). Accountability in corporation managed and traditionally managed nonprofit hospitals. Unpublished doctoral dissertation, Pennsylvania State University.

Cameron, K.S. (1980). Critical questions: Assessing organizational effectiveness. Organizational Dynamics, 9, 66-80. 
Connolly, T., Conlon, E.J., \& Deutsch, S.J. (1980). Organizational effectiveness: A multiple constituency approach. Academy of Management Review, , 5, 211-218.

Deprez, R.D., Pennell, B.E., \& Libby, M.A. (1987). The substatutability of outpatient primary care in rural community health centers for inpatient hospital care. Health Services Research, 2, 207-33.

Joint Rural Task Force of the National Association of Community Health Centers and the National Rural Health Association. (1989). Community health centers and the rural economy: The struggle for survival. Kansas City, MO: National Rural Health Association.

Keeley. M. (1978). A social justice approach to organizational evaluation. Administrative Science Quarterly, 23, 272-292.

Kirby, W., Latta, V., \& Helbing, C. (1986). Medicare use and cost of home health agency services, 1983-84. Health Care Financing Review, 7, 93-100.

Moscovice, I. (1989). Strategies for promoting a viable rural health care system. The Jourmal of Rural Health, 5, 216-230.

Movassaghi, H., \& Kindig, D. (1989). Medical practice and satisfaction of physicians in sparsely populated rural counties of the United States: Results of a 1988 survey, The lournal of Rural Health, 5, 125-136.

Office of Economic Opportunity. (1987). Profile of Vermont pozerty. Washington, DC: Author.

Prindaville, G.M., Sidwell, L.H., \& Milner, D.E. (1983). Integrating primary health care and mental health services-A successful rural linkage. Public Health Reports, 98, 67-72.

Reid, R.A., Bartlett, E.E., \& Kozoll, R. (1981). Implementation of the health center concept in a rural community: A case study. Journal of Community Health, 7, 57-66.

Reid, R.A., \& Smith, H.L. (1984). Integrating rural health care systems: Managerial implications for design and implementation. Journal of Ambulatory Care Management, 7, 13-28.

Ricketls, T.C., Konrad, T.R., Stein, J.S., \& DeFriese, G.H. (1987). Population ecology and health policy analysis: The case of rural primary care centers. Medical Care Review, 44, 345-374.

Ricketts, T.C., Wagner, E.H., \& Konrad, T.R. (1983). An evaluation of subsidized rural primary care programs II: The environmental contexts. American Journal of Public Health, 73, 406-413.

Sardell, A. (1988). The U.S. experiment in social medicine: The community health center program, 1965-1986, Pittsburgh. PA: University of Pittsburgh Press.

Sheps, C.G., Wagner, E.H., Schonfeld, W.H., DeFriese, G.H., Bachar, M., Brooks, E.F., Gillings, D.B., Guild, P.A., Konrad, R., McLaughlin, C.P., Ricketts, T.C., Seipp, C., \& Stein, J.S. (1983). An evaluation of subsidized rural primary care programs I: A typology of practice organizations. American Journal of Public Health, 73, 38-49.

Smith. D.G., \& Zuckerman, H.S. (in press). Perceptions of community leaders and the merger of rural health services. Journal of Community Health

Smith, H.L., \& Reid, R.A. (1987). Integrating hospice and home health services: Analysis of strategic factors. Home Health Care Services Quarterly, 8, 87-102.

Starkweather, D. B. (1981). Mergers in the Making. Ann Arbor, MI: Health Administration Press.

Vermont Department of Public Health. (1989). Report of vital statistics in Vermont. Burlington, V'T: Author.

Vermont Department of Public Health. (1988). Population and housing estimates, 1987. Burlington, V'T: Author.

Wheeler, J.R.C., \& Zuckerman, H.S. (1984). Hospital management contracts: Institutional and community perspectives. Health Services Research, 19, 499-518.

Whitehead, C.J., Blair, J.D., Smith, R.R., Nix, T.W., \& Savage, G.T. (1989). Stakeholder supportiveness and strategic vulnerability: Implications for competitive strategy in the HMO industry. Health Care Management Review, 14, 65-76.

Wood, J.B., Hughes, R.G., \& Estes, C.L. (1986). Community health centers and the elderly: A potential new alliance. Journal of Community Health, 11, 137-46. 